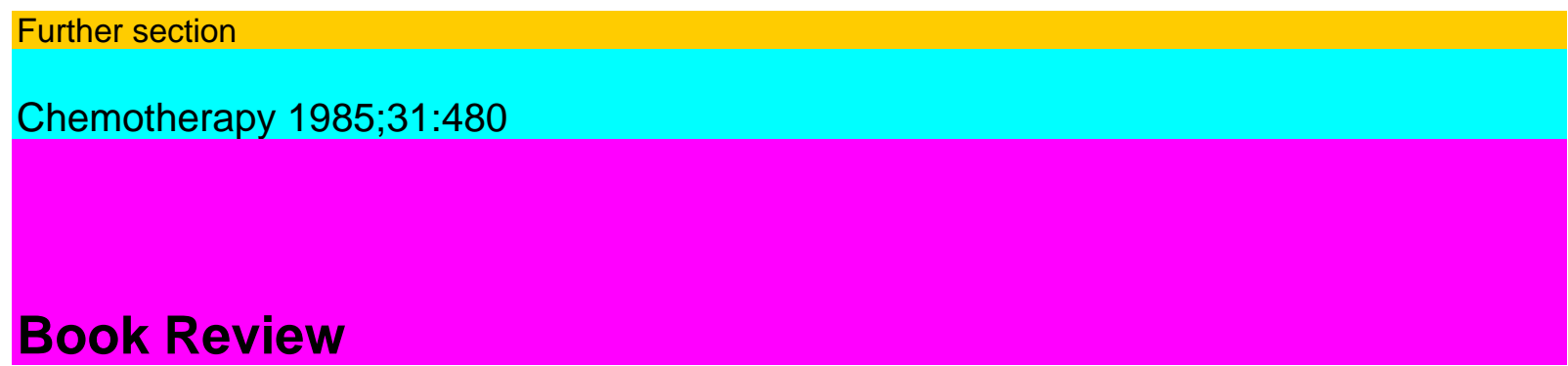

\title{
D. Shugar
}

Viral Chemotherapy, Vol. 1

Int. Encyclopedia of Pharmacology

\& Therapeutics, Section 111

Pergamon Press, Oxford 1984

XII + 573 pp.; $£$ 95.00/US \$ 145.00

ISBN 0-08-029821-4

This large book is a major undertaking for anyone interested in antiviral chemotherapy. The International Encyclopedia of Pharmacology and Therapeutics was conceived years ago as a source of current information as well as a reference work, presenting pharmacological and therapeutic data and concepts for the use of research workers, teachers of pharmacology and therapeutics, and to practicing physicians. The present volume, which is the first in a series on viral chemotherapy, and which will continue to be issued in the next year, fully meets those original concepts.

D. Shugar, a noted medicinal chemist of the University of Warsaw and editor of this series of volumes, points out in the preface that the concept of viral chemotherapy has not always been warmly received. Indeed, the idea of using a drug to treat viral infections has been subject to considerable skepticism up to only a few years ago because of the intimate relationships viruses have to host cells, resulting in what opponents felt would be an intolerable toxic effect on the host by any viral inhibitory material. The present series, which reviews in depth the significant known antiviral substances, begins to show what remarkable strides have been made in the viral chemotherapy field in the past 10 years. It becomes quite obvious that the field is expanding rapidly, and significant progress towards development of antiviral drugs has been made.

The editor has selected recognized authorities in the field to prepare each of the chapters in the volume, and these writers have done an excellent job in reviewing the information available on a number of

antiviral substances as well as to provide very appropriate background material for the subject. Emphasis was particularly placed on fundamental aspects of the respective subjects, with much discussion on mechanisms of action, where known, of the substances reviewed. The first two chapters, by F. Fenner, provide an overview of the nature and classification of viruses of man and their pathogenesis and frequency. The latter chapter is conveniently broken down by type of infection. E.C. Herrmann, Jr. and J. A. Herrmann review the concept of viral disease diagnosis, pointing out the need for early diagnosis to go hand-in-hand with viral chemotherapy. F.L. Black provides a short but comprehensive review of the current status of vaccines for the various viral diseases, as a means of focus on the virus infections which yet need cures. L. Carrasco discusses in considerable depth the mechanisms involved in the replication of animal viruses. A number of significant antiviral substances are then reviewed almost in the order of their discovery. These include amantadine, by J.S. Oxford and A. Galbraith; metal ions and metal chelating agents, by D.D. Perrin; aranucleosides and aranucleotides, by T.W. North and S. Cohen; iodi-nated 
pyrimidine deoxyribonucleotides, by W.H. Prusoff and 8 coworkers; azapyrimidine nucleosides, by B. Rada and J. Doskocil; single-stranded polynucleotides by N. Stebbing; photodynamic therapeutic materials, by L.E. Bockstahler and 3 co-workers; and antiviral immunopotentiating substances, by G. Werner and A. Zerial.

All references are fully cited, which will be of great value. It is obvious that additional volumes in this series are forthcoming since many of the newer and most significant antiviral substances are not included in this first volume. One would hope these future volumes are issued sooner so that this major review effort can be seen in its entirety.

Robert W. Sidwell, Logan, Utah 